\title{
Effect of Change of Hepatic Drug-Metabolizing Activity on Plasma Concentrations of Major Metabolites of the New Sleep Inducer 450191-S, a 1H-1,2,4-Triazolyl Benzophenone Derivative
}

\author{
Takashi MATSUBARA, Akira TOUCHI and Noriko YAMADA \\ Shionogi Research Laboratories, Shionogi \& Co., Ltd., Fukushima-ku, Osaka 553, Japan
}

Accepted April 30, 1987

\begin{abstract}
Plasma concentrations of the major metabolites of 450191-S, a new sleep inducer which is a $1 H-1,2,4$-triazolyl benzophenone derivative, were determined in rats. Under the HPLC conditions employed, several major metabolites were detected in plasma, and thus the plasma concentration-time profiles for these metabolites were checked in rats in various states. When the animals were pretreated with high doses of 450191 -S (200 or $600 \mathrm{mg} / \mathrm{kg}$ for 5 or 3 days, respectively) to induce hepatic drug-metabolizing enzymes, plasma concentrations of the metabolites after oral administration of a dose of $200 \mathrm{mg} / \mathrm{kg}$ of 450191 -S decreased markedly depending on the induced enzyme activity. Pretreatment of rats with phenobarbital also caused decreased plasma levels of metabolites, which were almost the same as those in 450191-S-pretreatment. On the other hand, administration of beta-naphthoflavone to rats led to higher plasma levels of metabolites, and slower elimination compared with those in the control and 450191-S- or phenobarbital-pretreated rats. These results indicate that plasma levels of metabolites are regulated by the drug-metabolizing enzymes in the liver. It also suggests the participation of some specific forms of cytochrome P-450 in the biotransformation of 450191 -S and its metabolites.
\end{abstract}

A wide variety of chemicals have been established to induce hepatic drugmetabolizing enzymes, which led to an increase in enzyme activities and also a high cytochrome P-450 content (1-3). The stimulation of hepatic enzyme activities by typical inducers such as phenobarbital is well known to modify the pharmacological and toxicological actions of drugs (4-6).

A new sleep inducer, 450191-S, 5[(2aminoacetamido)-methyl]-1-[4-chloro-2-(ochlorobenzoyl)phenyl]-N.N-dimethyl-1H-Striazole-3-carboxamide hydrochloride dihydrate, was demonstrated to stimulate the hepatic drug-metabolizing enzymes in rats, mice and dogs (7-9), which was accompanied by a marked reduction in the pharmacological activity of pentobarbital in rats (7). The induction of hepatic enzyme activities by 450191 -S was detected only when the plasma concentrations of its metabolites were very high (8). Thus, our attention was drawn to the plasma concentrations of metabolites in rats after the induction of hepatic enzymes. In this study. we compared the plasma profiles of 450191 $S$ metabolites in the 450191 -S-pretreated rats with those in rats pretreated with typical inducers, phenobarbital and beta-naphthoflavone. Here we provide the evidence that the administration of higher amounts of 450191 - $S$ results in the induction of hepatic drug-metabolizing enzymes followed by remarkable alteration in the plasma concentrations of 450191 -S metabolites similar to results with rats pretreated with the typical inducer phenobarbital, but not similar to those treated with beta-naphthoflavone.

\section{Materials and Methods}

Materials: $450191-S$ and authentic samples of its metabolites (M-1, M-2 and $M-3$ ) 
were synthesized at Shionogi Research Laboratories as described previously $(10,11)$. Other chemicals of the purest grade available were obtained commercially and used for the experiments without further purification.

Animals and their treatments: Adult male rats of the $J_{c}$ Sprague-Dawley strain, 7-8 weeks old, were used for the experiments. The animals were kept in an air-conditioned room $\left(25 \pm 1{ }^{\circ} \mathrm{C}, 50-60 \%\right.$ humidity) lighted $12 \mathrm{hr}$ a day (8:00-20:00) and maintained on commercial rat chow (CA-1, Clea Japan Inc., Tokyo) and water ad libitum. 450191-S was dissolved in $5 \%(w / v)$ arabic gum at 20 or $60 \mathrm{mg} / \mathrm{ml}$, and the resulting solution was administered crally to rats at $1.0 \mathrm{ml} / 100 \mathrm{~g}$ body weight for 3-5 days. Typical inducers. phenobarbital (in physiological saline) and beta-naphthoflavone (in sesame oil). were administered intraperitoneally at a dose of $40 \mathrm{mg} / \mathrm{kg}$, once daily for 3 days. The animals were fasted for $24 \mathrm{hr}$ after the last administration of 450191 - $S$ or inducers, and then the test solution of $450191-\mathrm{S}(20 \mathrm{mg} / \mathrm{ml}$ of $5 \%$ arabic gum) was given orally to rats at a dose of $200 \mathrm{mg} / \mathrm{kg}$. Heparinized blood samples were obtained from the abdominal aorta under ether anesthesia and centrifuged immediately to obtain plasma samples using an Eppendorf centrifuge Type 5414S.

HPLC analysis of metabolites in rat plasma: Major metabolites of 450191 - S (M-1. M-2 plus $M-D$ and $M-3$ plus $M-A$ ) in rat plasma was detected by high performance liquid chromatography (HPLC) as described previously (8). Metabolites in rat plasma were extracted with ethanol under acidic conditions. Then, plasma components in the extract were removed by the transfer of the extract to acetate buffer $(\mathrm{pH} \mathrm{5.0)}$, followed by the Sep-Pak $\mathrm{C}_{18}$ treatment as described previously (8), and the final evaporated samples were dissolved in alkaline solution $\left(0.1 \mathrm{M} \mathrm{Na}_{2} \mathrm{CO}_{3}\right)$. Metabolites $\mathrm{M}-\mathrm{D}$ and $\mathrm{M}-\mathrm{A}$ were detected as $\mathrm{M}-2$ and $\mathrm{M}-3$, respectively, by this alkaline treatment. HPLC analysis was carried out with an instrument equipped with a Waters Model 6000A pump, a Waters U6K universal injector, a Shimadzu SPD-2A detector (set at $254 \mathrm{~nm}$ ) and a Shimadzu CRIB chromatopac. The column employed was Nucleosil $5 \mathrm{C}_{18} \quad(4.6 \mathrm{~mm} \times 15 \mathrm{~cm})$ with a precolumn of Nucleosil $10 \mathrm{C}_{18} \quad(4.0 \mathrm{~mm} \times 5$ $\mathrm{cm})$. The mobile phase was $\mathrm{P} \mid \mathrm{C}-\mathrm{A}$, and an acetonitrile mixture $(650: 350, \mathrm{~V} / \mathrm{V})$ at a flow rate of $1.5 \mathrm{ml} / \mathrm{min}$. One vial of $\mathrm{PIC}-\mathrm{A}$ (Waters ${ }^{\mathrm{TM}} \mathrm{PIC}^{\mathrm{B}}$ reagent $\mathrm{A}$ ) was dissolved in $650 \mathrm{ml}$ of $\mathrm{H}_{2} \mathrm{O}$ and used as a component of the mobile phase. Known amounts of authentic samples of metabolites were analyzed under the same conditions, and the plasma concentrations of metabolites were calculated by comparing the peak area of each metabolite with that of the corresponding sample.

Determination of hepatic drug-metabolizing activity: Rat liver samples obtained were homogenized in $0.25 \mathrm{M}$ sucrose con-

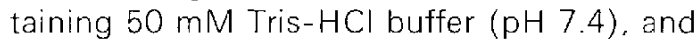
7 -alkoxycoumarin $\mathrm{O}$-dealkylase activity was determined using the liver homogenate as described previously (12).

\section{Results}

Plasma concentrations of metabolites in rats after oral administration of high dose of 450191-S: The main metabolic pathway of $450191-S$ in several laboratory animals was established as depicted in Fig. $1(11,13,14)$ Several major metabolites (M-1, M-D. M-2, $M-A$ and $M-3$ ), but not the parent compound $450191-S$ and the metabolite $M-4$. were detectable in rat plasma, although metabolites $M-D$ and $M-A$ were detected as M-2 and $M-3$, respectively, under the analytical conditions employed (8). The appearance and clearance profiles of major metabolites of 450191 - $S$ were studied in rats administered a high dose $(200 \mathrm{mg} / \mathrm{kg})$ of the drug. The higher plasma level of metabolite M-1 was obtained 30-120 min after the administration, and then its plasma concentration decreased gradually. Metabolites M-2 plus M-D showed the highest concentration at 2-4 hr after the treatment, and their peak concentration was very high compared with that of $\mathrm{M}-1$. Then, the plasma level of these metabolites decreased gradually, but higher plasma level was observed continuously until $6 \mathrm{hr}$ after the treatment. On the other hand, the plasma concentration of metabolites M-3 p/us M-A increased gradually, and the peak was observed $4-6 \mathrm{hr}$ after the administration (Fig. 2A). Since the 


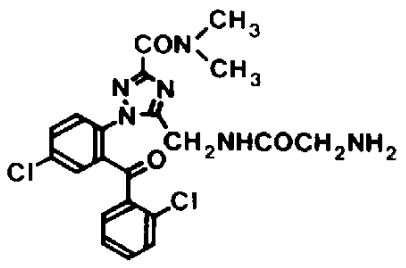

450191-S

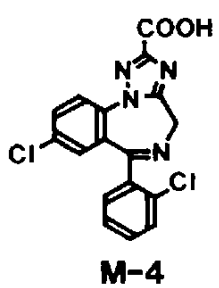

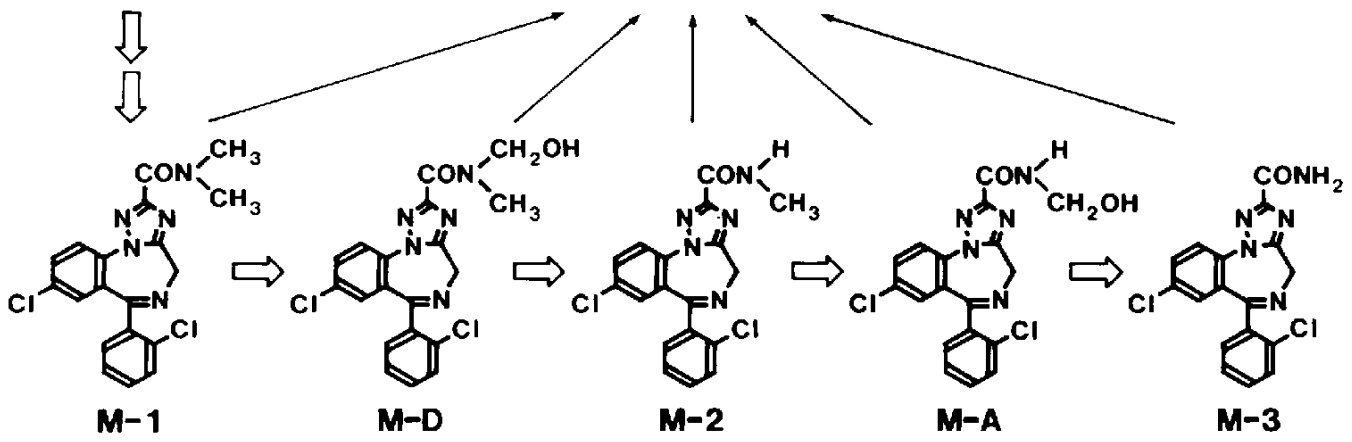

Fig. 1. Main metabolic pathways of 450191 -S.

plasma levels of M-D and $M-3$ were very low (8), metabolites showing higher plasma concentrations were assumed to be $\mathrm{M}-2$ and $\mathrm{M}-\mathrm{A}$. The results shown in Fig. 2A indicate that the metabolic conversion of metabolite M-1 to $M-2$ was followed by that to $M-A$. as described previously (14); and the conversion of $M-2$ to $M-A$ was supposed to be a rate-limiting step in the major pathway of 450191-S metabolism when high amounts of 450191 -S were administered.

Effect of pretreatment of rats with higher doses of 450191-S on plasma metabolite concentration: As reported previously (7-9). successive administrations of higher amounts of 450191-S induce liver cytochrome P-450dependent drug-metabolizing enzymes and modify the pharmacological action of pentobarbital. It suggested the modified or altered pharmacodynamic profiles of 450191 $S$ itself after the induction of hepatic drugmetabolizing enzymes by 450191 - $S$ administration. Thus, the plasma concentrations of 450191-S metabolites in rats pretreated with higher amounts of the drug were compared with those in control rats. The animals were given 450191 - $\mathrm{S}$ at a dose of 200 or $600 \mathrm{mg} /$ $\mathrm{kg}$ for 5 or 3 days, respectively, to induce the liver enzyme activity (7). After the last administration, the animals were fasted for
$24 \mathrm{hr}$, and then 450191 - $S$ was given orally at $200 \mathrm{mg} / \mathrm{kg}$ to determine the plasma concentrations of metabolites. When animals were pretreated with the drug at $200 \mathrm{mg} / \mathrm{kg}$ for 5 days, the plasma level of metabolite $M-1$ was almost the same as that in the control rats, but it decreased faster, being at an undetectable level $4 \mathrm{hr}$ later. Plasma M-2 plus M-D concentrations in the pretreated rats were highest at $2 \mathrm{hr}$ after the administration and then decreased rapidly. The time course of the appearance of metabolites $M-3$ plus $M-A$ was similar to that of $M-2$ plus $M-D$, and the highest level was observed between 2 and $4 \mathrm{hr}$ after the administration followed by a rapid decrease (Fig. 2B).

Plasma concentration-time profile for major metabolites of $450191-S$ in rats pretreated with the highest dose of the drug $(600 \mathrm{mg} /$ $\mathrm{kg}$ ) showed a different pattern from that in control rats. As shown in Fig. 2C, the peak concentration of metabolite $M-1$ was obtained 15-60 min after the administration, although its level was very low. On the other hand, the peak concentrations of metabolites $\mathrm{M}-2$ plus $\mathrm{M}-\mathrm{D}$ and $\mathrm{M}-3$ plus $\mathrm{M}-\mathrm{A}$ were obtained at 1 and $2 \mathrm{hr}$, respectively. The highest concentrations of all metabolites detected were very low in the pretreated rats when compared with those in control rats. 
(A) Contral

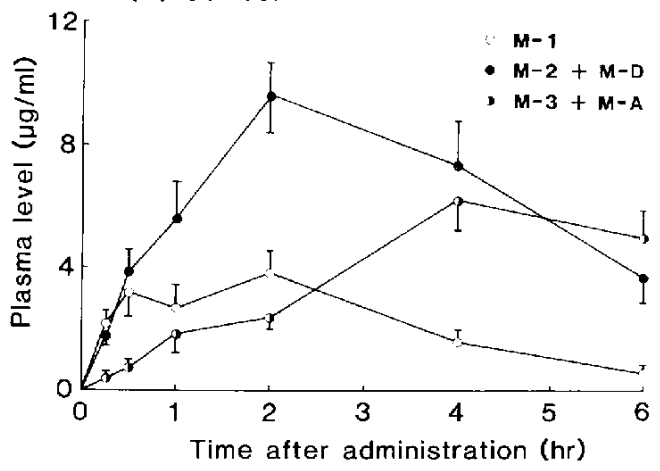

(C) $450191-\mathrm{s}(600 \mathrm{mg} / \mathrm{kg})$

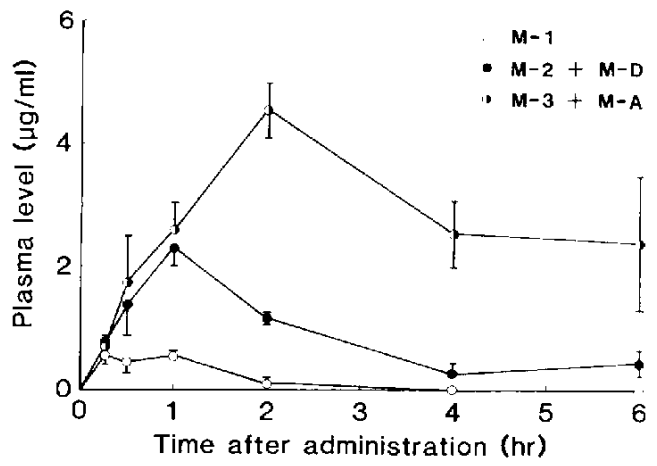

The results shown in Fig. 2 probably indicate that the induction of hepatic drug-metabolizing enzymes in rats by the administration of higher doses of 450191-S increased the metabolic ability for 450191 -S itself and reduced the plasma level of the major metabolites.

Effects of phenobarbital and betanaphthoflavone on plasma metabolite concentration: Phenobarbital and beta-naphthoflavone are known as typical inducers of specific forms of cytochrome P-450 (1-3, 15). To obtain the correlation between the induction of specific forms of cytochrome $P$. 450 and the plasma metabolite levels of 450191-S, animals were pretreated with phenobarbital or beta-naphthoflavone as described in "Methods". 450191-S was administered to the pretreated rats at 200 $\mathrm{mg} / \mathrm{kg}$, and the appearance and clearance kinetics of the metabolites were studied to compare the profiles with those in control
(B) 450191-S (200mg/kg)

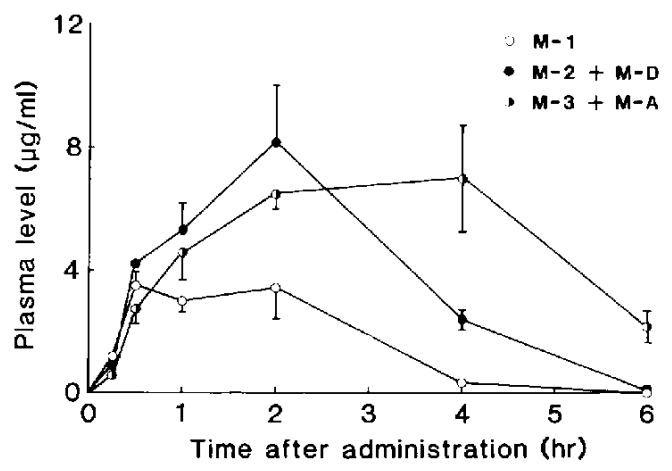

Fig. 2. Plasma concentration-time profiles for metabolites of 450191-S in control and 450191-Spretreated rats. The rats received $450191-S$ orally at doses of 200 or $600 \mathrm{mg} / \mathrm{kg}$. once daily for 5 or 3 days, respectively. The animals were fasted for $24 \mathrm{hr}$ after the last administration, and then 450191-S (200 $\mathrm{mg} / \mathrm{kg}$ ) was administered to determine the plasma metabolite levels. Blood samples were obtained at the time points shown in the figures. The animals in the control group were given 450191-S alone for metabolite determination. (A) control rats, (B) 450191 -S-pretreated rats given $200 \mathrm{mg} / \mathrm{kg}$ for 5 days, and (C) 450191 -S-pretreated rats given 600 $\mathrm{mg} / \mathrm{kg}$ for 3 days. Each point represents the mean $t$ S.E. of 4 rats.

and 450191-S-pretreated rats. The plasma metabolite concentration-time profile in phenobarbital-pretreated rats (Fig. 3A) showed a pattern similar to that in the 450191-S-pretreated rats administered the highest dose of the drug. On the other hand. the profile of plasma metabolite concentrations in beta-naphthoflavone-pretreated rats (Fig. 3B) differed markedly from the control and phenobarbital- or 450191-Spretreated rats. The concentration of metabolite M-1 was highest $1 \mathrm{hr}$ after the administration and then decreased. The highest plasma concentration of metabolite M-2 plus M-D was also observed $1 \mathrm{hr}$ after the treatment; these metabolites appeared quickly in plasma and disappeared at a slow rate. The plasma level of metabolites $M-3$ plus M-A was, on the other hand, elevated slowly and the highest concentrations were obtained at or later than $6 \mathrm{hr}$. The results shown in Fig. 3 indicate probably that a 
(A) Phenobarbital

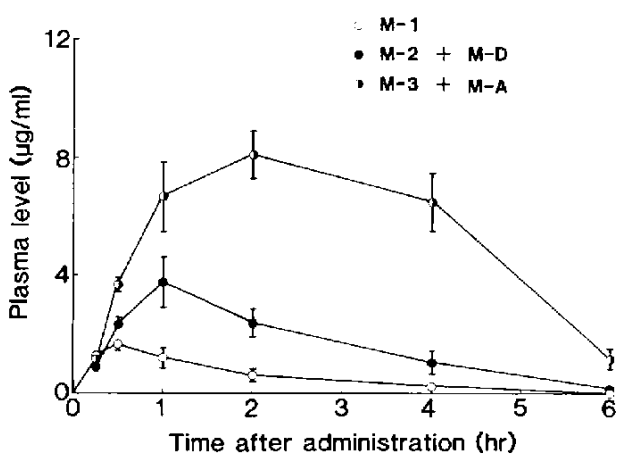

(B) $\beta$-Naphthoflavone

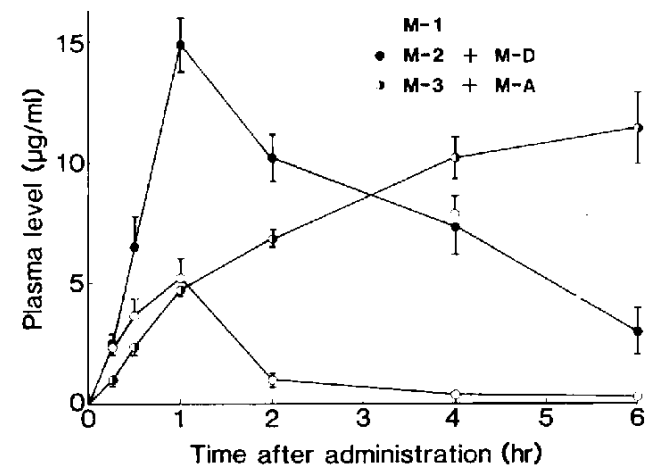

Fig. 3. Effects of phenobarbital and beta-naphthoflavone administration on plasma concentrations of metabolites. The rats were given intraperitoneally phenobarbital (A) or beta-naphthoflavone (B) at a dose of $40 \mathrm{mg} / \mathrm{kg}$ for 3 days and then fasted for $24 \mathrm{hr}$ after the last administration. Test drug 450191-S was administered orally $(200 \mathrm{mg} / \mathrm{kg})$ to the fasted animals, and its major metabolites in plasma were analyzed. Each point represents the mean \pm S.E. of 4 animals.

Table 1. Hepatic 7 -alkoxycoumarin 0 -dealkylase activity

\begin{tabular}{|c|c|c|c|c|}
\hline \multirow{2}{*}{$\begin{array}{l}\text { Exptl } \\
\text { group }\end{array}$} & \multirow{2}{*}{$\begin{array}{c}\text { Treatment } \\
\text { of rat }\end{array}$} & \multicolumn{3}{|c|}{ Activity (nmol/min/g liver) } \\
\hline & & $\begin{array}{l}\text { 7-Methoxycoumarin } \\
\text { O-demethylase }\end{array}$ & $\begin{array}{l}\text { 7-Ethoxycoumarin } \\
\text { Q-deethylase }\end{array}$ & $\begin{array}{c}\text { 7-Propoxycoumarin } \\
\text { O-depropylase }\end{array}$ \\
\hline 1 & $\begin{array}{l}\text { Control } \\
450191-S\end{array}$ & $\begin{array}{c}80.5 \pm 7.9 \\
130.7 \pm 2.7^{*}\end{array}$ & $\begin{array}{c}97.9 \pm 5.5 \\
220.8 \pm 22.7^{* *}\end{array}$ & $\begin{array}{c}95.6 \pm 8.5 \\
175.7 \pm 24.4^{*}\end{array}$ \\
\hline 2 & $\begin{array}{l}\text { Control } \\
\text { Phenobarbital }\end{array}$ & $\begin{array}{c}55.0 \pm 2.9 \\
154.1 \pm 10.2^{* *}\end{array}$ & $\begin{array}{c}85.4 \pm 3.4 \\
257.7 \pm 14.7^{* *}\end{array}$ & $\begin{array}{l}112.8 \pm 7.8 \\
266.4 \pm 10.9^{* *}\end{array}$ \\
\hline 3 & $\begin{array}{l}\text { Control } \\
\beta \text {-Naphthoflavone }\end{array}$ & $\begin{array}{l}53.4 \pm 2.0 \\
58.6 \pm 4.6\end{array}$ & $\begin{array}{c}83.9 \pm 4.2 \\
355.5 \pm 24.8^{* *}\end{array}$ & $\begin{array}{l}118.3 \pm 7.8 \\
332.4 \pm 25.1^{* *}\end{array}$ \\
\hline 4 & $\begin{array}{l}\text { Control } \\
450191-S\end{array}$ & $\begin{array}{l}77.7 \pm 1.8 \\
45.1 \pm 2.0^{* *}\end{array}$ & $\begin{array}{l}\text { n.d. } \\
\text { n.d. }\end{array}$ & $\begin{array}{l}\text { n.d. } \\
\text { n.d. }\end{array}$ \\
\hline
\end{tabular}

In Exptl groups 1-3, animals were given $450191-\mathrm{S}(600 \mathrm{mg} / \mathrm{kg}$, p.o.) or inducers $(40 \mathrm{mg} / \mathrm{kg}$, i.p.), once daily for 3 days, and liver samples were obtained $24 \mathrm{hr}$ after the last administration. In Exptl group 4 . animals were given orally $450191-S(200 \mathrm{mg} / \mathrm{kg})$, and liver samples were obtained $6 \mathrm{hr}$ after the administration. The values in the table represent the mean \pm S.E. of 4 animals. n.d.: not determined. **** statistically significant ( $P<0.05$ and $P<0.01$, respectively) against the corresponding control.

specific form(s) of cytochrome P-450 participates in metabolizing $450191-S$ and the related metabolites in a different manner.

Hepatic drug-metabolizing activity: Cytochrome P-450-dependent 7-alkoxycoumarin O-dealkylase activity $(12,16-18)$ in rat livers was determined to check the correlation between hepatic drug-metabolizing activity and plasma concentration of 450191-S metabolites. Hepatic Odemethylation, O-deethylation and O-de- propylation activities were all stimulated markedly in rats pretreated with 450191 -S or phenobarbital, while beta-naphthoflavone treatment caused a remarkable increase only in O-deethylation and O-depropylation activities, but not in $\mathrm{O}$-demethylation activity (Table 1. Exptl groups 1-3). The results demonstrated that the inductive pattern in 450191-S-pretreated rats was similar to that in phenobarbital-pretreated animals, but not similar to that in beta-naphthoflavone-pre- 
treated rats. The increased O-dealkylation activities in 450191-S-pretreated rat liver microsomes were inhibited only by anti bodies against phenobarbital-inducible forms of cytochrome P-450, and the increase in cytochromes $P-450 \mathrm{~b}$ and $\mathrm{P}-450 \mathrm{e}$ was detected in liver microsomes obtained from 450191-S-pretreated rats (T. Matsubara and $Y$. Funae, unpublished results). These results support the above conclusion. When liver samples were obtained from the rats $6 \mathrm{hr}$ after the treatment of 450191-S, O-demethylase activity was suppressed markedly in these livers (Table 1. Exptl group 4). It indicates probably that 450191 - 5 metabolites and 7-methoxycoumarin are metabolized by the same form(s) of cytochrome P-450.
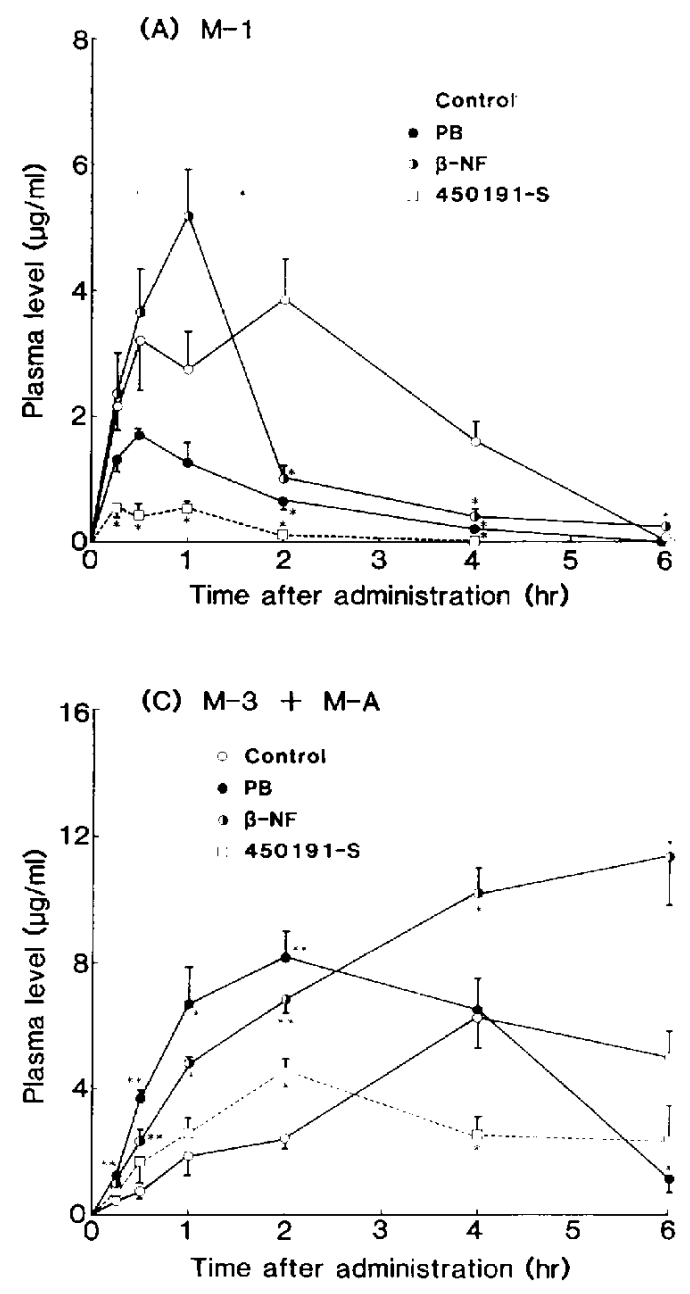

\section{Discussion}

Koike et al. (19) have studied the absorption and distribution of ${ }^{14} \mathrm{C}$-labeled $450191-S$ in rats and found that deglycylation of the parent drug by aminopeptidase in intestinal mucosa during the absorption process seems to be followed by cyclization to form the metabolite $M-1$. The dimethylcarbamoyl side chain group of metabolite $M-1$ is then sequentially oxidized to several metabolites as depicted in Fig. 1. These metabolites are mainly excreted to bile (14), and thus their hepatocellular distribution is thought to be the most important factor for understanding the correlation between the hepatic enzyme activity and the

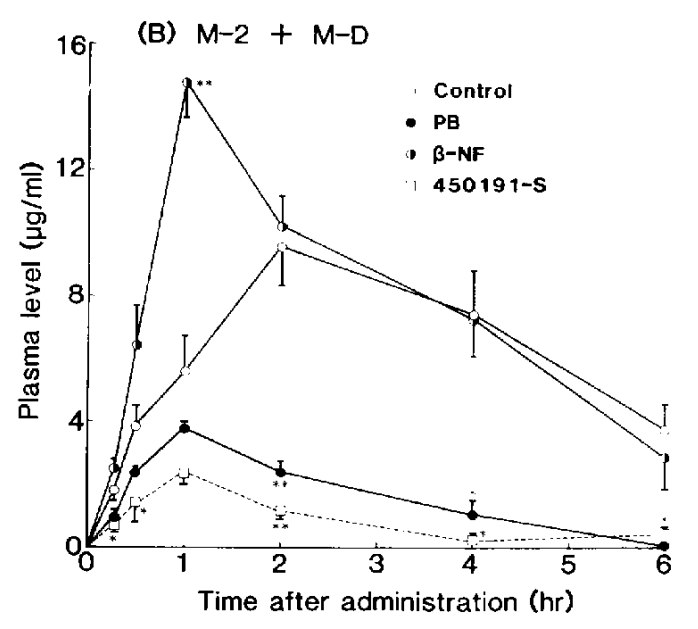

Fig. 4. Comparison of plasma concentrations of metabolites in control and treated rats. The results shown in Figs. 2 and 3 were rearranged and plotted. Figures (A), (B) and (C) represent the plasma concentration-time profiles for metabolites $M-1$. M-2 plus $\mathrm{M}-\mathrm{D}$ and $\mathrm{M}-3$ plus $\mathrm{M}-\mathrm{A}$, respectively. Animals of the $450191-\mathrm{S}$ pretreatment group received $600 \mathrm{mg} / \mathrm{kg}$ doses of the drug for 3 days. Phenobarbital (PB) and beta-naphthoflavone ( $\beta$ NF) were given at $40 \mathrm{mg} / \mathrm{kg}$ for 3 days. ${ }^{*},{ }^{*}$ : significantly different from the control, $P<0.05$ and $P<0.01$, respectively. 
levels of 450191-S metabolites. However, the plasma level profiles of the metabolites may reflect the metabolic pattern in liver, and they are also important for obtaining therapeutic correlations. From this point of view. we checked the plasma concentrations of metabolites in rats of various states. Although only metabolites $\mathrm{M}-1, \mathrm{M}-2$ and $\mathrm{M}-3$ were detected under the assay conditions employed, most of the $\mathrm{M}-3$ detected is derived from $M-A$, and the actual concentration of $M-3$ in rat plasma is very low (8). Similarly. the $M-D$ concentration is negligibly low in rat plasma (8).

The analytical data shown in Figs. 2 and 3 were used to compare the plasma concentrations of various metabolites as shown in Fig. 4. The rate of the appearance of M-1 in plasma was almost the same among animals of various states (Fig. 4A), suggesting no alteration in the rate of the absorption process in rats under the experimental conditions employed. As depicted in Fig. 1, metabolite M-1 is converted enzymatically to $M-2$ via the formation of M-D. and the lower plasma concentration of metabolite $\mathrm{M}-1$ even at the peak level suggests its rapid conversion to M-D plus $\mathrm{M}-2$ in rats pretreated with phenobarbital or $450191-\mathrm{S}(600 \mathrm{mg} / \mathrm{kg})$. Metabolites $M-2$ plus $M-D$ were further converted to $M-3$ via the formation of $M-A$ (14). and the lower plasma concentrations of $\mathrm{M}-2$ plus M-D in phenobarbital- or 450191-Spretreated rats (Fig. 4B) suggest the rapid conversion of $\mathrm{M}-2$ to $\mathrm{M}-\mathrm{A}$ and other ring hydroxylated metabolites. Rapid formation of M-3 plus $M-A$ in phenobarbital-pretreated rats (Fig. 4C) support the above assumption. On the other hand. Iower plasma concentrations of $\mathrm{M}-3$ p/us $\mathrm{M}-\mathrm{A}$ in 450191-Spretreated rats suggest the rapid formation of ring hydroxylated metabolites followed by the formation of conjugates, which are easily excreted into the bile. The plasma level profiles of major metabolites suggest that the metabolic steps converting $\mathrm{M}-1$ to $\mathrm{M}-\mathrm{D}$ and M-2 to $M-A$ are stimulated or induced when animals are treated with phenobarbital or 450191-S. In vitro metabolic conversion of 450191-S metabolites was studied using ${ }^{14} \mathrm{C}$-labeled metabolites (M-1, M-2, M-A and $\mathrm{M}-3$ ) and isolated liver microsomes, which demonstrated the increased metabolism of these metabolites in phenobarbital- and $450191-S$-treated rat liver microsomes. Formation of ring hydroxylated metabolites was also observed in the incubation system using these microsomes (T. Matsubara and K. Kawamoto, unpublished results). The results agreed well with the in vivo profiles of metabolites, and the data will be reported in the near future.

Plasma concentration-time profiles for metabolites in beta-naphthoflavone-pretreated rats showed quite different patterns from those in phenobarbital- and 450191-Spretreated animals, indicating the highest piasma level of the metabolites and slow clearance: very high plasma concentration of metabolites $\mathrm{M}-2$ plus $\mathrm{M}-\mathrm{D}$ and slower formation of metabolites $\mathrm{M}-3$ plus $\mathrm{M}-\mathrm{A}$ (Fig. $4)$. The results suggest that the liver enzymes participating in the conversion from $\mathrm{M}-2$ to $\mathrm{M}-\mathrm{A}$ are not induced by beta-naphthoflavone. Higher peak concentration of me tabolite $\mathrm{M}-1$ in beta-naphthoflavonepretreated rats suggests also the slower conversion of M-1 to $M-D$ and ring hydroxylated metabolite(s). Kawamoto et al. also demonstrated the slower conversion of $\mathrm{M}-1$ and $M-2$ and the formation of different ring hydroxylated metabolites in the in vitro reaction system when liver microsomes obtained from beta-naphthoflavone-pretreated rats were used for the assay (unpublished results). Ditferent inductive profiles of the O-dealkylation activity in beta-naphthoflavone-treated rat livers from those in phenobarbital- or 450191-S-treated rat livers (Table 1) suggest also the differences between beta-naphthoflavone- and 450191 $S$-treatments. These results indicate that the pharmacokinetic profiles of 450191-S metabolites in 450191-S-pretreated rats are almost the same as those in phenobarbitalpretreated rats, but not similar to those in beta-naphthoflavone-pretreated animals.

\section{References}

1 Conney, A.H.: Pharmacological implications of microsomal enzyme induction. Pharmacol. Rev. 19, 317-366 (1967)

2 Sher, S.P.: Drug enzyme induction and drug interactions; literature tabulation. Toxicol. Appl. 
Pharmacol. 18, 780-834 (1971)

3 Lu, A.Y.H. and West, S.B.: Multiplicity of mam. malian cytochrome P-450. Pharmacol. Rev. 31, 277-295 (1980)

4 Golberg, L.: Liver enlargement produced by drugs. Its significance. In Proc. Eur. Soc. Study Drug Toxicity, Edited by Alcock, S.J., Baker. S.B. de C., Scott, A.I. and Tucker, M.J., Vol. VII, p. 171-184, Excerpta Medica Foundation, Amsterdam (1966)

5 Hunter, J. and Chasseaud, L.F.: Clinical aspects of microsomal enzyme induction. In Progress in Drug Metabolism, Edited by Bridges, J.W. and Chasseaud, L.F., Vol. 1, p. 129-191, John Wiley \& Sons, London (1976)

6 Remmer, H., Fleischmann, R. and Kunz, W.: Pharmacological consequences of induction of drug metabolizing enzymes. In The induction of Drug Metabolism, Edited by Estabrook, R.W. and Lindenlaub. E., p. 555-581, F.K. Schattauer Verlag. Stutgart (1979)

7 Matsubara, T., Touchi, A., Yamada, N. and Nishiyama, S.: Effect of a new sleep inducer. 1H-1,2,4-triazolyl benzophenone derivative. 450191-S on rat liver drug-metabolizing enzyme system. Folia Pharmacol. Japon. 86, 115-127 (1985) (Abs in English)

8 Matsubara, T., Touchi, A., Yamada, N. and Sugeno, K.: Induction of rat liver microsomal drug-metabolizing enzymes by a new sleep inducer 450191 -S and plasma level of 450191 S-metabolites. J. Pharmacobiodyn. 9, 249-256 (1986)

9 Koike, M., Futaguchi, S., Sugeno, K., Touchi, A. and Matsubara, T.: Autoinduction of 450191-S. a new sleep inducer of $1 H-1.2 .4$-triazolyl benzophenone derivative, in dogs. J. Pharmacobiodyn. 9, 909-916 (1986)

10 Hirai, K., Sugimoto, H., Ishiba, T., Fujishita, T., Tsukinoki, $Y$. and Hirose, K.: Synthesis and biological activity of $(3,5$-disubstituted $1 \mathrm{H}$ 1.2,4-triazol-1-yl) benzophenone derivatives. J. Heterocyclic Chem. 19, 1363-1369 (1982)

11 Fujimoto, M., Hashimoto, S., Takahashi, S. Hirose, K., Hatakeyama, $H$. and Okabayashi, T. Detection and determination of active metabolites of 1-(2-o-chlorobenzoyl-4-chloro- phenyl) - 5-glycyl-aminomethyl-3-dimethylcarbamoyl-1H-1,2,4-triazole hydrochloride derivative, (450191-5), in rat tissue using a radioreceptor assay for benzodiazepines. Biochem. Pharmacol. 33, 1645-1651 (1984)

12 Matsubara, T., Otsubo, S., Yoshihara, E. and Touchi, A.: Biotransformation of coumarin derivatives. (2) Oxidative metabolism of 7 alkoxycoumarin by microsomal enzymes and a simple assay procedure for 7 -alkoxycoumarin 0 dealkylase. Japan. J. Pharmacol. 33, 41-56 (1983)

13 Yamamoto, K., Hirose, K., Matsushita, A., Yoshimura, K., Sawada, T., Eigyo, M., Jyoyama, H., Fujita, A., Matsubara, K., Tsukinoki, Y., Hatakeyama, H., Shiomi, T., Ibii, N., Inoue, S. and Koshida, H.: Pharmacological studies of a new sleep inducer, $1 H-1,2,4$-triazolyl benzophenone derivatives (450191-S). (1) Behavioral analysis. Folia Pharmacol. Japon. 84, 109-154 (1984) (Abs. in English)

14 Koike, M., Norikura, R., Yoshimori, T., Futaguchi, S. and Sugeno, K.: Biopharmaceutical characterization of 450191 - $S$, a ring-opened derivative of 1,4-benzodiazepane. 1. Active metabolite levels in rat plasma. J. Pharmacobiodyn. 9, 563569 (1986)

15 Guengerich, F.P.: Isolation and purification of cytochrome $P-450$, and the existence of multiple forms. Pharmacol. Ther. 6, 99-121 (1979)

16 Ulurich, V. and Weber, P.: The O-dealkylation of 7-ethoxycoumarin by liver microsomes. A direct fluorometric test. Hoppe Seylers Z. Physiol. Chem. 353, 514-520 (1973)

17 Kamataki, T., Ando, M., Yamazoe, Y., Ishii, K. and Kato, R.: Sex difference in the O-dealkylation activity of 7-hydroxycoumarin $\mathrm{O}$-alky! derivatives in liver microsomes of rats. Biochem. Pharmacol. 29, 1015-1022 (1980)

18 Imai, Y.: Reconstituted O-dealkylase system containing various forms of liver microsomal cytochrome P-450. J. Biochem. (Tokyo) 86, 1697-1707 (1979)

19 Koike, M., Norikura, R. and Sugeno, K.: Intestinal activation of a new sleep inducer 450191-S, a $1 \mathrm{H}$-triazolyl benzophenone derivative in rats. $J$. Pharmacobiodyn, 9, 315-320 (1986) 